\title{
Hai loại sáng tạo, hai giai đoạn đời người (được giải Nobel)
}

\author{
Hồ Mạnh Toàn
}

Al for Social Data Lab

4-10-2019

Hai nhà nghiên cứu tới từ Ohio State University và University of Chicago Chicago, B.A. Weinberg và D.W. Galenson công bố nghiên cứu ngày 26-4-2019 rất có ý nghĩa động viên (với những người xưa nay bị quan niệm sai là đã "quá tuổi sáng tạo"). Nghiên cứu này khá dài và có thể đọc toàn văn, miễn phí (nhờ xuất bản truy cập mở) trên tạp chí De Economist [1].

Nghiên cứu này được tới vài quỹ khoa học lớn cùng tài trợ: National Science Foundation, National Institute on Aging, National Institutes of Health's Office of Behavioral and Social Sciences Research, Ewing Marion Kauffman and Alfred P. Sloan foundations.

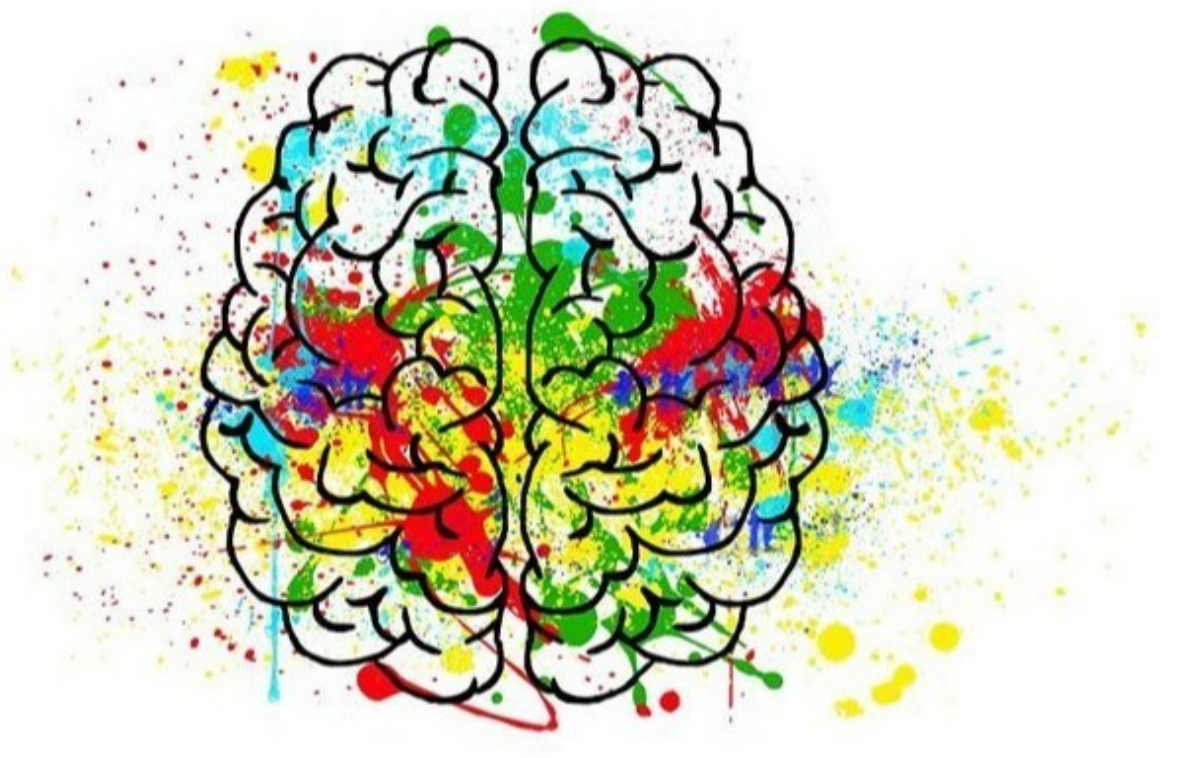

Nói ngắn gọn, kết quả của 2 ông phát biểu rằng, trong lĩnh vực khoa học kinh tế, những nhà nghiên cứu sau này được nhận phần thưởng cao quý nhất là giải thưởng Nobel Kinh tế cơ bản cho thấy 2 kiểu loại năng lực sáng tạo, và tương ứng với 2 giai đoạn của đời người.

Kiểu loại sáng tạo thứ nhất, chính là quan niệm quen thuộc của chúng ta: Sáng tạo đột biến về nhận thức, ở tầm tuổi giữa thời kỳ đôi mươi (khoảng 25 đổ ra). Kiểu người sáng tạo này tiêu biểu cho "suy nghĩ vượt thoát các giới hạn điều kiện hiện tại" mang tính thách thức trí khôn truyền thống, và mang đến các tư tưởng mới khá đột ngột. Những người đại diện cho kiểu sáng 
tạo này thường nảy sinh ý tưởng và hoàn thành ngay lúc trẻ, trước khi họ nhúng mình sâu đậm vào một trường phái nghiên cứu lớp lang dày dặn.

Đặc trưng loại 1 là logic sắc bén, mới mẻ, triển khai toán học, cách chứng minh.

Kiểu loại sáng tạo thứ hai, thường không được chú ý nhiều là sáng tạo dựa trên cơ sở thực nghiệm. Khoảng thời gian phổ biến cho loại năng lực này khoảng giữa ngũ tuần. Những người tiểu biểu cho kiểu loại này thường tích lũy rất nhiều kiến thức và suy nghĩ riêng qua thời gian, chiêm ngẫm và rồi phát kiến ra cách thức đột phá mở đường cho tiếp cận phân tích mới mẻ, cách diễn giải và tập hợp thông tin tạo ra tri thức mới. Ở nhóm này, các thời kỳ dài làm việc, chấp nhận các phép thử và sai lầm là cơ sở quan trọng để nảy sinh đột biến sáng tạo.

Đặc trưng loại 2 là dữ liệu, phương pháp tiếp cận, kỹ thuật phân tích và lăng kính đọc ra các kết quả đột biến.

Hai tác giả cho biết nhiều khả năng kết quả của công bố này không giới hạn trong giới kinh tế học, mà có thể hoàn toàn tương đồng với cả các ngành khoa học khác. Nếu đúng như vậy, kiểu loại sáng tạo có tương quan chặt chẽ với tiếp cận logic hay dữ liệu.

Nói thêm về tiếp cận khung lý thuyết các phương pháp. Trước đây chừng 5-6 năm đã có các nghiên cứu và công bố với logic khá tương đồng trên Int J Trans Innov Syst năm 2015 [2], trong đó 3 tiếp cận năng lực sáng tạo đã đề cập đến cả 2 kiểu loại trên, và có đề cập thêm 1 tiếp cận nữa là "serendipity" [3].

Note: Published in EASE Vietnam SciComm System: https://sc.sshpa.com/post/5562

\section{References:}

[1] Weinberg, B. A. \& Galenson, D. W. (2019). Creative careers: The life cycles of Nobel laureates in economics. De Economist, 167(3), 221, DOI: 10.1007/s10645-019-09339-9

[2] Vuong, Q. H., \& Napier, N. K. (2014). Making creativity: the value of multiple filters in the innovation process. International Journal of Transitions and Innovation Systems, 3(4), 294-327.

[3] Napier, N. K., \& Vuong, Q. H. (2013). Serendipity as a strategic advantage?. In Wilkinson (ed) Strategic Management in the 21st Century (Vol. 1: The Operational Environment, pp. 175-199). Westport, CT: Praeger/ABC-Clio. 